\title{
Table of Statutes
}

Arbitration (Scotland) Act 2010

s $1 \ldots \ldots \ldots \ldots \ldots \ldots \ldots . \ldots . \ldots 124$

Sch 1 (Scottish Arbitration Rules)

rr $67,68,69,70 \ldots \ldots \ldots \ldots 125$

Bankruptcy (Scotland) Act 2016

s $2(1)$ (b) . . . . . . . . . . . . 113

s $7(1) \ldots \ldots \ldots \ldots \ldots \ldots \ldots . \ldots 113$

s $16(1)(f) \ldots \ldots \ldots \ldots \ldots \ldots \ldots 114$

(i) $\ldots \ldots \ldots \ldots \ldots \ldots 112,113$

(3)(b) . . . . . . . . . 113

Bankruptcy and Diligence etc (Scotland)

Act 2007

s 183 114

s 208 112

Buildings (Scotland) Act 2003 . . . . . . 86

Court of Session Act 1988

s $47(1) \ldots \ldots \ldots \ldots \ldots$. . . . . . . 60

(2) $\ldots \ldots \ldots \ldots \ldots \ldots 59,73$

(2A)................ 59

Courts Reform (Scotland) Act 2014 s $88 \ldots \ldots \ldots \ldots \ldots \ldots \ldots . \ldots 73$

(1)(b) .............. 59

Debt Arrangement and Attachment

(Scotland) Act 2002

s 19

Debtors (Scotland) Act 1987 ss 73J, 73L

114

Disability Discrimination Act 1995 s $21(2)(a)-(c) \ldots \ldots \ldots \ldots \ldots \ldots . . .53$

Equality Act 2010 s 20
Factories Act 1961.... . . . . . . . . 53

Fire (Scotland) Act 2005 . . . . . . . . . . 53

Health and Safety at Work Act 1974 . . . 53

Insolvency Act 1986

s $122 \ldots \ldots \ldots$. . . . . . . . . . 113

s $123 \ldots \ldots \ldots \ldots \ldots \ldots \ldots . \ldots \ldots$

(1) . . . . . . . . . . . 113

(a) ............ . 112

Landlord and Tenant Act 1927

s $18 \ldots \ldots \ldots \ldots \ldots \ldots 6$. 62, 63

Law Reform (Miscellaneous Provisions)

(Scotland) Act 1940

s $1 \ldots \ldots \ldots \ldots \ldots \ldots \ldots$. . . . . . . 58

Law Reform (Miscellaneous Provisions)

(Scotland) Act 1985 . . . . . . 71, 117

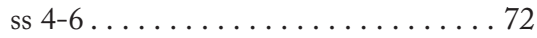

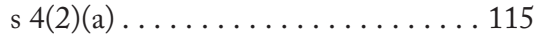

(3), (4) . . . . . . . . . . . 115

s $5 \ldots \ldots \ldots \ldots \ldots \ldots$ 72, 78, 84

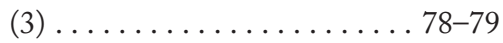

Legal Writings (Counterparts and

Delivery) (Scotland) Act 2015 . . . . . . 46

Occupiers' Liability (Scotland) Act 1961..................... . 86

Office, Shops and Railway Premises Act 1963. . . . . . . . . . . . . . . 53

Requirements of Writing (Scotland) Act 1995. . . . . . . . . . . . . . . . . 46

Tenements (Scotland) Act 2004 . . . . . 87 